\title{
LA EDUCACION COMO FENOMENO SOCIAL *
}

\section{Émile Durkheim}

En el primero de estos artículos, nos hemos dirigido a establecer de manera general que el arte de la pedagogía tiene necesidad de recurrir a la sociología tanto como a la Psicología. En efecto, la educación es una cosa eminentemente social. Es social por su fin. Lejos está de que tenga por objeto realizar la naturaleza individual del hombre en general; ella varía de una sociedad a otra. Primero, en el momento en que las sociedades han conseguido un cierto grado de diferenciación, se la ve diferenciarse en sí misma siguiendo las clases, las profesiones. Ahora bien, esta especialización es dictada por necesidades sociales; pues la educación responde a la forma en la cual el trabajo social está dividido y organizado en cada momento de la historia. Es verdad que todas estas educaciones especiales no divergen más que a partir de cierto punto más allá del cual se confunden. Pero al mismo tiempo esta educación común es función del estado social; pues cada sociedad busca realizar en sus miembros, por la vía de la educación, un ideal que le es propio. Las mismas sociedades europeas más avanzadas no escapan a esta ley. Estamos sin duda en lo correcto cuando decimos que deseamos hacer hombres de nuestros niños, y no solamente ciudadanos en el estrecho sentido de la palabra. Pero es que solo una cultura verdaderamente humana puede dar a los pueblos europeos los ciudadanos que requiere. En sociedades tan vastas como las nuestras, los individuos son tan diferentes los unos de los otros, que no hay, por así decir, nada de común entre ellos, salvo su cualidad general de hombre. Todavía hay que agregar que cada nación se hace del hombre una concepción que le es, en parte, personal, dado que refleja sus necesidades, su mentalidad especial, su pasado histórico, etc.

En resumen, la educación, lejos de tener simplemente por fin desarrollar al hombre tal como sale de las manos dc la naturaleza, tiene por objeto extraer de allí un hombre enteramente nuevo; crea un ser que no existe, salvo en el estado de germen indiscernible: el ser social. Ella es la que nos enseña a dominarnos, a constreñirnos; es también, siguiendo sus necesidades, la que decide la cantidad y naturaleza dc los conocimientos que debe recibir el niño, y lo mismo que es a través de ella que se conserva la ciencia adquirida por las generaciones anteriores, es también la que la transmite a las nuevas generaciones. Es, pues, la que forma en nosotros todo lo que supera la esfera de las puras sensaciones: nuestra voluntad como nuestro entendimiento son moldeados a su imagen.

La acción social se hace sentir hasta en la naturaleza de los medios empleados para atender este fin. Sin duda, estos medios varían según la noción que nos hagamos de la conciencia de los niños y, por consiguiente, de los hechos de la Psicología, sobre todo de la Psicología infantil. Ante todo, silos fines perseguidos por la educación son sociales, los medios deben tener necesariamente el mismo carácter. $Y$ en efecto, las instituciones pedagógicas son a menudo una forma de verdaderas instituciones sociales. Por ejemplo, la disciplina escolar tiene los mismos rasgos esenciales de la disciplina de la ciudad. Más

\footnotetext{
* Publicado originalmente en L'Année Sociologique, vol VII, 1904, pp. 684-686. Contiene la reseña de dos ensayos: a) E. Durkheim, Pedagogía y sociología", Revue de métaphysique et morale, enero de 1903 reproducido en E. Durkheim, Educación y sociología, Bogotá, Editora Babel, 1976], y b) Paul Barth, "l-listoria de la educación a la luz de la sociología", Viertejiahrschift für' wissenschaftliche Philosophie und Soziologie, 1903. 
aún, la naturaleza del fin determina la de los métodos. Tales procederes son proscritos o buscados porque están o no de acuerdo con la concepción que la sociedad se hace del ideal a alcanzar. Lo que ha suscitado el método pestalozziano, por ejemplo, es el sentimiento que tenía su autor de las aspiraciones morales de su tiempo, mucho más que su ciencia psicológica.

Estas son las mismas ideas que sustentan el trabajo de Paul Barth. De hecho, el autor quiere mostrar históricamente cómo la educación ha variado en su forma y en su contenido según las sociedades.

He aquí los principales resultados a los cuales él llega. Primero que todo, no encuentra ningún lazo entre la organización familiar y la naturaleza de la educación; y nosotros creemos, en efecto, que aquélla está más directamente ubicada bajo la dependencia de la organización general de la sociedad. Un factor importante sería la naturaleza de la industria. En los pueblos cazadores y pescadores, había una ausencia general de toda disciplina educativa. El niño era abandonado a sí mismo, sin obligarlo a contenerse y a resistirse. Las ocupaciones de estos pueblos son irregulares, caprichosas; por consiguiente, no sienten la necesidad de someter a los niños a una regla severa. La regularidad es mayor en los pastores y en los agricultores; además, estas sociedades son más inclinadas por las guerras. Atacan y son atacadas porque la tierra tiene para ellas un valor que no existía anteriormente. La educación pone por lo tanto al niño a resistir ante sus pasiones; le infunde valor, de suyo lo obliga a la subordinación. Este reforzamiento de la disciplina se acentúa aún más en los agricultores superiores tales como los primeros griegos y los germanos de Tácito. La cultura y el arte de la guerra se hacen más difíciles, las técnicas militar y agrícola, que eran enseñadas a los niños, se complicarán en la misma medida; al mismo tiempo, una mayor severidad fue exigida en las costumbres domésticas. En fin, allá donde la sociedad se organiza en clases, la educación se convierte, ella misma, en una función especializada. De otro lado, se diversifica según los medios, variando de una clase á otra; y se complica en razón de la complejidad mayor de la vida social.

Una revisión tan rápida de una multitud de pueblos diversos, no permitieron al autor, por supuesto, emplear documentos de primera mano, y, por la misma razón, las conclusiones a las cuales llega son todavía muy generales. Pero este intento de ligar directamente la educación con las condiciones sociales de las cuales depende, merecían ser subrayadas. 